\title{
Fluxes and production efficiency of irrigated wheat ecosystem under edaphic constraints of western Maharashtra plateau: a micrometeorological investigation
}

\author{
SUNAYAN SAHA*, S. K. BAL and K. P. BHAGAT ${ }^{1}$ \\ ICAR-National Institute of Abiotic Stress Management, Baramati, Pune, Maharashtra, India \\ ${ }^{1}$ ICAR-Central Citrus Research Institute, Nagpur-440033, India \\ *E-mail: sunayan.iari@gmail.com; sunayan.saha@icar.gov.in
}

\begin{abstract}
Energy fluxes and canopy microclimate of wheat grown on the edaphically stressed shallow basaltic soil at Baramati, India were studied during 2014-15. The crop was grown with optimum irrigation, applied at frequent intervals, resulting in a low seasonal Bowen ratio (H/LE: Sensible heat flux/Latent heat flux) value of 0.23 . The diurnal average flux rate for $\mathrm{H}$ during various phenophases varied between 2.2 and $16.2 \mathrm{Wm}^{-2}$ and had a seasonal mean of $11.0 \mathrm{~W} \mathrm{~m}^{-2}$. LE exchange rates varied between 44.2 and $56.8 \mathrm{Wm}^{-2}$ and the seasonal mean was $49.0 \mathrm{~W} \mathrm{~m}^{-2}$. Evapo-transpiration (ET) of wheat in the location under standard growing condition was estimated at $312 \mathrm{~mm}$. However, the crop could actually evapotranspire water in the range of 187-248 mm,as measured through an eddy covariance based protocol, even though it received about $410 \mathrm{~mm}$ of water through irrigation and rainfall. Canopy condition were interpreted through hyperspectra based indices, viz. NDVI and LSWI which indicated atleast two instances of stress, one around maximum tillering and the other between anthesis and dough stages.Net primary production and yield during the 105 day long growing season were $558 \mathrm{~g} \mathrm{C} \mathrm{m}^{-2}$ and $3.3 \mathrm{t} \mathrm{ha}^{-1}$, respectively and the productivity gap could be minimized by addressing the major edaphic limitations, i.e. low soil volume and high seepage losses.
\end{abstract}

Keywords : Fluxes, wheat, edaphically stressed, eddy covariance, hyperspectra, ET

Wheat is the second most important staple food crop of India after rice, cultivated in about 29.8 million hectare (Singh et al., 2015) spreading over six zones with distinct agro-climatic conditions (Annual Report, DWR, 2012-13). Realizing the genetic yield potential or maximizing net biomass carbon gain is a matter of proper crop stress management which mainly depends on water availability and irrigation scheduling. Water management regulates energy partitioning within the crop microclimate and various fluxes at the crop-atmosphere interface, thus have relevance to climate change. To develop effective mitigation and adaptation practices it is pertinent to study among others the potential crop water requirement vis-a-vis actual water footprint in relation to energy fluxes and productivity of crop in a given environment. Such information will help in deciding best water allocation strategy to various crops ensuring economic production or maximizing water productivity.

The landscape of western Maharashtra is part of the deccan plateau which has about $6 \%$ share of country's wheat acreage. The region has chronic water scarcity and crop productivity here would get affected by multiple abiotic stresses such as terminal heat and water and at places due to edaphic factors such as low soil volume and stoniness of the soil profile. Lysimeter and field water balance methods have been traditionally used for crop water requirement studies in India (Bandyopadhyay and Mallick, 2003;Tyagi et al., 2000). Nowadays, integrated area based measurements using state-of-the art eddy covariance technique is increasingly being adopted under major scientific programs. This offers the scope of a comprehensive study on crop micro-meteorology including energy fluxes, evapotranspiration that are required for developing or improving vegetation productivity models and validation of satellite based land surface data products (Baldocchi et al., 2001; Morisette et al., 2002; Xiao et al., 2008). However, such studies so far have been rare in India (Bhattacharya et al., 2013). This study was conceived to investigate the interrelations of crop micro-environment, energy fluxes, actual crop water use, stress and evapo-transpiration gap of a wheat ecosystem using eddy covariance and ground based hyper spectral remote sensing.

\section{MATERIALS AND METHODS}

\section{Site features}

The study was carried out at the research farm of the 


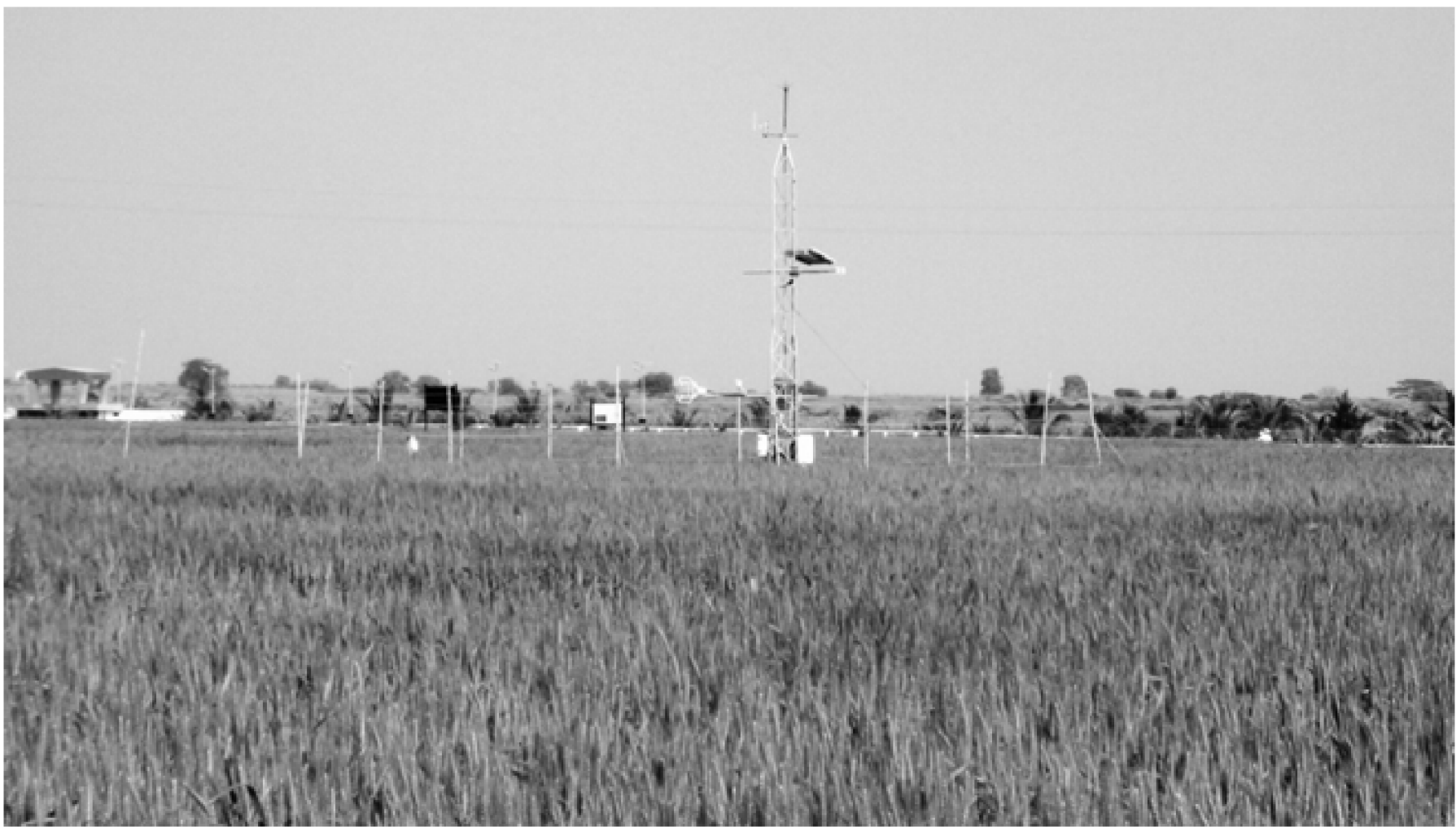

Fig. 1 : Flux measurement over wheat at ICAR-NIASM(2014-15)

ICAR-National Institute of Abiotic Stress Management (NIASM), Baramati (Latitude: $18^{\circ} 09^{\prime}$ N, Longitude: 74³0' E, average elevation: $\sim 550 \mathrm{~m}$ AMSL), situated in the western part of central India in the Deccan plateau of Indian peninsula. The area is characterized by semi-arid type of climate with monsoon and post monsoon rains. Winter is short, moderate and remains mostly rainless. Long-term average annual rainfall of the station is $588 \mathrm{~mm}$. The major soil groups of the area are Ustorthents, Ustropepts and Chromusterts belonging to the orders vertisols, inceptisols and entisols. The soils are of basaltic origin, mostly shallow to medium in depth, well drained and have slight stoniness. Overall fertility status of the soil is low as these are low in nitrogen $\left(\leq 280 \mathrm{~kg} \mathrm{~N} \mathrm{ha}^{-1}\right)$ and low to medium in phosphorus $(\leq 25 \mathrm{~kg}$ $\left.\mathrm{Pha}^{-1}\right)$, however, potash content is medium to high $(\geq 121 \mathrm{~kg}$ $\left.\mathrm{Kha}^{-1}\right)$.

\section{Crop management}

Wheat was grown during the rabi/winter season of 2014-15 in south-side farm of NIASM that had only 2-3 years of cropping history. As the native basaltic soil (murrum) of the research farm was very shallow with presence of parent rock materials in less than $50 \mathrm{~cm}$ depth, a portion of it was topped with a layer of black soil to obtain at least $50 \mathrm{~cm}$ depth in order to improve water retention and reduce edaphic constraints to certain extent. The above soil layer was sandy clay to silty clay in texture, had a bulk density of about $1.3 \mathrm{Mgm}^{-3}$, $\mathrm{PH}$ (1:2.5 soil:water) $8.3, \mathrm{EC} 0.24 \mathrm{dSm}^{-1}$, Organic Carbon $6.4 \mathrm{~g} \mathrm{~kg}^{-1}$, available N:P:K 173:20:145 kg $\mathrm{ha}^{-1}$ and volumetric soil moisture contents were 33 and $15 \%$ at field capacity ( 0.33 bar) and permanent wilting point ( 15 bar), respectively.

A contiguous area of about 2 ha surrounding an eddy covariance flux tower with fetch length in principal directions from the sensors varying between $75-150 \mathrm{~m}$ or more (Fig. 1), was sown with wheat using tractor driven seed drill wherein a seed rate of $90 \mathrm{~kg} \mathrm{ha}^{-1}$ was used. About $80 \%$ of the area was under a single variety, viz.HD-2189.A basal dose of 75:60:40 kg ha- ${ }^{-1}$ of $\mathrm{N}_{2} \mathrm{P}_{2} \mathrm{O}_{5}$ and $\mathrm{K}_{2} \mathrm{O}$ was applied while another $75 \mathrm{kgNha}^{-1}$ was top dressed during the vegetative phase around 40 DAS. One irrigation was provided at sowing for better germination and others during different growth phases (hereafter has been denoted as phase I to V), viz. between sowing to CRI/crown root initiation (I: 1-15 DAS; 1 no.), tillering (II: 16-40 DAS; 1 no.), maximum tillering to anthesis (41-65 DAS; 2 no.), flowering to dough (66-90 DAS; 1 no.) and dough to maturity (91-105 DAS; 1 no.). The Nira canal water which was used for irrigation had $\mathrm{pH}$ and EC values around 7.6 and $0.26 \mathrm{dSm}^{-1}$, respectively. The rainfall received during the 105 days long crop growth period (14-Nov, 2014 -26-Feb, 2015) was $51.7 \mathrm{~mm}$ that 
occurred in 5 no. of rainy days and out of which 4 fell within the first phase (at 2, 3, 5 and 6 DAS) itself and the remaining $7.6 \mathrm{~mm}$ at $31 \mathrm{DAS}$.

\section{Flux measurements and data processing}

A flux tower equipped with an eddy covariance system (open path type) was installed in the middle of the NIASM research farm. It provided spatially integrated measurements of turbulent fluxes (the quantity of certain entity that moves through unit area per unit time) of sensible and latent heat at the crop-atmosphere interface. The system was composed of two fast response sensors, viz., a three dimensional (3-D) sonic anemometer (CSAT3, Campbell Scientific) and an open path type infrared gas analyser (EC150, Campbell Scientific) from which measurements of wind, sonic temperature and water vapour density were obtained. To ensure that the above two measurements are done in the identical sample volume of air, the aforesaid sensors were placed minimally apart with no vertical separation and the mid-axis horizontal separation distance a mere $5 \mathrm{~cm}$. Slow response research grade sensors were fitted to the tower for continuous monitoring of micrometeorological conditions near the surface (two four component net radiometers: NR01, Hukseflux; one sensor for ambient temperature: HMP155A, Campbell Scientific) and some sensors (two heat flux sensors: HFP01, Hukseflux; two soil moisture sensors: CS616, Campbell Scientific and two soil temperature sensors: TCAV, Campbell Scientific) were deployed inside the soil within the cropped area for monitoring the soil heat flux, temperature and moisture near the surface root zone.A built-in programme in the data logger (CR-3000, Campbell Scientific) performed synchronization among those sensors during data acquisition, then processed and stored data it in a memory card in DAT format. These data was then converted in a computer terminal using LoggerNet software into ASCII Table data format that contained 10 Hzraw time series data as well as processed data in half-hourly time scale for various fluxes and environmental variables measured diurnally. The program computed mean vertical flux density (Fz) of sensible and latent heat at 30 minutes time scale as covariance between deviations in instantaneous vertical wind speed $(w)$ and air temperature (c) for the former and water vapour density (c) for the latter flux terms (Baldocchi, 2003; Burba, 2005). Mean air density and other terms such as specific heat of air and latent heat for vaporization were also required to compute and convert the fluxes into suitable energy units.

$$
\mathrm{Fz}=\bar{a} * \overline{w^{\prime} c^{\prime}}
$$

Where, " $\alpha$ " refers to density of air, the over bars denote time averaging and the primes represent fluctuations from mean value. In this study, turbulent fluxes with positive sign indicate net transfers into the atmosphere whereas a negative sign is usedto represent net downward flow i.e. towards the crop canopy or ground surface. The datalogger programme took into account the flux density changes due to fluctuations in temperature and water vapour densities and applied WPL (Webb, Pearman and Leuning)-corrections (Webb et al., 1980) to the measured flux.

ASCII files consisting of half-hourly data were exported in Microsoft Excel and stringent quality control criteria were adopted to remove suspicious or bad quality flux data. These include data acquired during precipitation events or data associated with poor signal strength, eddies disturbed by the tower hardware infrastructure (when wind flew from the back of the EC-150 and CSAT-3 sensors), stable atmospheric condition, noise and spikes. The gaps in the half-hourly time series were filled using mean diurnal variation (MDV) technique wherein diurnal means for consecutive 7-days windows were computed and replaced within it. The gaps which still remained were filled using linear moving average method.

\section{Biophysical observations}

To characterize biophysical conditions of wheat a total of 50 observational spots were selected across the footprint area in a zig-zag manner. Observations were recorded on leaf area index (LAI) using a portable leaf area meter (The AccuPAR model LP-80, Decagon devices, USA) and canopyreflectance in $350-2500 \mathrm{~nm}$ range ( $1 \mathrm{~nm}$ interval) using a hyperspectral spectroradiometer (model: Fieldspec 4, ASD Inc., USA) at 4-5 days intervals. The above parameters were measured between 1100 and $1300 \mathrm{hrs} \mathrm{in} \mathrm{clear} \mathrm{sky} \mathrm{days.}$ Plant samples were collected during various phenophases and at harvest. All the plants within one meter square area were cut just above the soil surface and then dried in a hot air oven at $67^{\circ} \mathrm{C}$ for 48 hours for determining actual above ground net primary production i.e. the resultant of photosynthetic gain and respiratory losses or the net biomass carbon gain. For yield enumeration the total grain harvest in the footprint area was weighed just after harvest and converted to unit area (per hectare) yield.

\section{Stress factors}

During the season, biotic interferences such as 
insects-pests or weeds were completely controlled by chemical and mechanical means. The composite effect of various abiotic stress factors such as temperature, soil moisture, nutrients etc. was quantified in terms of the parameter, fAPAR (fraction of photosynthetically active radiation absorbed by the plant canopy). fAPARwas computed from a hyperspectral vegetation index (NDVI) based regression equation (Sims, et al., 2006). Beside fAPAR, relative water status of the soil crop canopy system was interpreted based on the Land Surface Water Index (LSWI) (Xiaoet al., 2008) which was also calculated from the hyperspectral data using the following formula:

$$
L S W I=\left(\rho_{\mathrm{NIR}}-\rho_{\mathrm{SWIR}}\right) /\left(\rho_{\mathrm{NIR}}+\rho_{\mathrm{SWIR}}\right)
$$

Where, $\rho_{\text {NIR }}$ and $\rho_{\text {SWIR }}$ represents reflectance of MODIS bands $2(841-876 \mathrm{~nm})$ and $6(1628-1652 \mathrm{~nm})$, respectively.

\section{Evapo-transpiration}

Reference crop evapo-transpiration $\left(\mathrm{ET}_{0}\right)$ was computed using two methods described in irrigation and drainage paper no. 56 of Food and Agricultural Organization (FAO). One method used Penmann-Monteith equation (Allen et al., 1998) where directly measured values of net radiation, ground heat flux, wind speed and vapour pressure were used. In second method of ET ${ }_{0}$ computation, first daily pan coefficients $(\mathrm{Kp})$ were computed from the look up table (class A Pan case) based on wind speed and relative humidity classes and pan siting in the field (FAO Irrigation and Drainage Paper No. 24). Then daily Pan evaporation data were multiplied with corresponding Kp to obtain $\mathrm{ET}_{0}$. For, computing evapo-transpiration of wheat under standard conditions ( $\mathrm{ET}_{\mathrm{c}}$-wheat), Kc values were first obtained from look up tables described in FAO 56 that required information on location, planting time, duration of growth phases, freezing or non-freezing condition of the soil and maximum crop height. Daily Kc values along with $\mathrm{ET}_{0}$ estimates were used to compute $\mathrm{ET}_{\mathrm{c}}$-wheat. Actual evapo-transpiration (AET) of wheat was computed from latent heat flux measurement by the eddy covariance system.

\section{RESULTS AND DISCUSSION}

\section{Footprint microclimate conditions}

Mean day length period during the wheat growing season was $11.3 \mathrm{hr}$ and the mean daily duration of brought sunshine (BSS) was $9.2 \mathrm{hrs}$. A meagre $51.7 \mathrm{~mm}$ rainfall occured in 5 no. of rainy days, however, the distribution was heavily skewed as four of the five days fell within the first week of sowing. Daily minima and maxima of temperature varied between $7.1-34.4{ }^{\circ} \mathrm{C}$, seasonal average of daily mean temperature was $21.2^{\circ} \mathrm{C}$ and that of soil temperature at 10 $\mathrm{cm}$ depth was $22.9{ }^{\circ} \mathrm{C}$. Total heat unit accumulation was $1752{ }^{\circ} \mathrm{C}$-Day. Mean wind speed over the crop canopy at 2 $\mathrm{m}$ height was $0.9 \mathrm{~m} \mathrm{~s}^{-1}$. Daily mean VPD was as low as $1.3 \mathrm{k}$ $\mathrm{Pa}$. Among the radiation parameters, seasonal mean insolation intercepted at the canopy surface was $17.7 \mathrm{MJ} \mathrm{m}$ ${ }^{2} \mathrm{~d}^{-1}$ whereas the outgoing long wave radiation and net radiation were 36.9 and $8.6 \mathrm{MJ} \mathrm{m}^{-2} \mathrm{~d}^{-1}$, respectively. Mean albedo of the soil crop surface from phase I to phase $\mathrm{V}$ ranged between 0.12 and 0.19 and had a seasonal mean of 0.17 . Growth Phase wise statistics of various micrometeorological parameters are provided in Table 1.

\section{Crop biophysical dynamics and stress}

Spectral vegetation index, NDVI increased very rapidly for the first four-five weeks after sowing and reached near saturation when LAI was about 2.0. For a further two fold increase in LAI, changes in NDVI was only marginal and at saturation (54 DAS) NDVI was 0.87 against an LAI of about 3.5. Maximum in the footprint area average LAI was found to be 4.2 (Fig.2) which was observed at 71 DAS. Being a linear function of NDVI, fAPAR remained maximum $(0.89$ 0.91) during 54-71 DAS.

Soil moisture dynamics during the growing season was mainly in response to the irrigation cycle (Fig. 3) as there were no significant rainfall events except during the first 15 DAS phase. Volumetric fraction of soil moisture on daily basis varied between 0.12 and 0.26 . Among the phenophases mean soil moisture status was highest in phase $\mathrm{I}(0.22)$ which also explains the initial high rate of crop growth. The crop experienced abiotic stress on account of sub optimal soil and plant water condition in the footprint area in atleast two instances. The first one was during 32-43 DAS when LAI was increasing rapidly but not the LSWI and fAPAR.The second instance of stress occurred during 71-79 DAS i.e. in phase IV when decrease in LSWI and AAPAR was very sharp although senescence had not started (Fig. 3). The fourth phase had also the lowest mean value of soil moisture content (0.16).

For most part of the growing season, as reflected from the ambient temperature, apparently there was no temperature stress. However, the senescence phase set in around 89 DAS and the crop was harvest ready at 105 DAS due to terminal heat stress i.e. sudden exposure to high level of net radiation and ambient temperature which caused rapid senescence and hastened maturity. Application of irrigation between 93-96 DAS could not delay the crop maturity. 
Table 1 : Land surface parameters and prevailing microclimatic conditions over the wheat ecosystem during the growing season of 2014-15

\begin{tabular}{|c|c|c|c|c|c|c|c|c|c|c|}
\hline $\begin{array}{l}\text { Time Period } \\
\text { (DAS) }\end{array}$ & $\begin{array}{l}\text { Tmean } \\
\left({ }^{\circ} \mathrm{C}\right)\end{array}$ & $\begin{array}{l}\text { BSS } \\
\left(\mathrm{hr} \mathrm{d}^{-1}\right)\end{array}$ & $\begin{array}{l}\text { Tsoil__ } \\
\text { mean } \\
\left({ }^{\circ} \mathrm{C}\right)\end{array}$ & $\begin{array}{l}\text { Heat } \\
\text { Units } \\
\left({ }^{\circ} \mathrm{C}-\right. \\
\text { Day) }\end{array}$ & $\begin{array}{l}\mathrm{VPD} \\
(\mathrm{kPa})\end{array}$ & $\begin{array}{l}\mathrm{WS}_{2} \\
\left(\mathrm{~ms}^{-1}\right)\end{array}$ & $\begin{array}{l}\text { Rs_in } \\
\left(\mathrm{MJm}^{-2}\right. \\
\left.\mathrm{d}^{-1}\right)\end{array}$ & $\begin{array}{l}\text { Rl_out } \\
\left(\mathrm{MJm}^{-2}\right. \\
\left.\mathrm{d}^{-1}\right)\end{array}$ & $\begin{array}{l}\mathrm{Rn} \\
\left(\mathrm{MJm}^{-2}\right. \\
\left.\mathrm{d}^{-1}\right)\end{array}$ & Albedo \\
\hline $\begin{array}{l}14-28 \text { Nov } \\
(1-15)\end{array}$ & 22.5 & 8.8 & 24.5 & 271 & 0.9 & 1.0 & 16.0 & 37.8 & 8.6 & 0.12 \\
\hline $\begin{array}{l}24 \text { Dec } 14 \text { to } 17 \text { Jan } \\
(41-65)\end{array}$ & 19.1 & 9.0 & 21.3 & 365 & 1.1 & 0.9 & 17.0 & 35.7 & 7.8 & 0.18 \\
\hline $\begin{array}{l}18 \text { Jan. to } 11 \mathrm{Feb} \\
(66-90)\end{array}$ & 21.5 & 9.4 & 22.7 & 424 & 1.4 & 0.9 & 18.2 & 37.0 & 9.1 & 0.18 \\
\hline $\begin{array}{l}\text { Seasonal } \\
\text { Mean/Total }\end{array}$ & 21.2 & 9.2 & 22.9 & 1752 & 1.3 & 0.9 & 17.7 & 36.9 & 8.6 & 0.17 \\
\hline
\end{tabular}

N.B. Rl_out - Outgoing long wave radiation; Rn - Net Radiation; Rs_in - incoming shortwave radiation; WS - Wind speed at $2 \mathrm{~m}$ height from ground surface

Table 2:Energy fluxes (latent heat, sensible heat and soil heat)in the diurnal cycle during various growth phases

\begin{tabular}{|c|c|c|c|c|c|c|c|c|c|}
\hline Growth Stage & \multicolumn{3}{|c|}{$\mathrm{LE}\left(\mathrm{Wm}^{-2}\right)$} & \multicolumn{3}{|c|}{$\mathrm{H}\left(\mathrm{Wm}^{-2}\right)$} & \multicolumn{3}{|c|}{$\mathrm{SH}\left(\mathrm{Wm}^{-2}\right)$} \\
\hline I (Sowing-CRI) & 169.2 & -4.4 & 56.8 & 95.5 & -18.1 & 16.2 & 1.2 & -6.9 & -2.9 \\
\hline II (CRI - MT) & 136.4 & 3.3 & 45.8 & 109.6 & -28.3 & 15.0 & 1.6 & -7.0 & -2.6 \\
\hline III (MT - ANTH) & 159.4 & 2.3 & 49.3 & 72.4 & -32.9 & 2.2 & 0.8 & -6.7 & -2.9 \\
\hline $\mathrm{V}(\mathrm{DO}-\mathrm{MAT})$ & 155.8 & 5.4 & 48.9 & 124.4 & -41.6 & 11.6 & 4.2 & -4.1 & 0.2 \\
\hline Seasonal & 169.2 & -4.4 & 49.0 & 124.4 & -41.6 & 11.0 & 4.2 & -7.0 & -1.8 \\
\hline
\end{tabular}

LE- Latent Heat Flux; H- Sensible Heat Flux; SH- Soil Heat Flux; Rn-Net Radiation; MT-Maximum Tillering; ANTH-Anthesis; DO - Dough; MAT - Maturity

Table 3: Growth phase wise estimates of evapo-transpiration of wheat

\begin{tabular}{lrrrrr}
\hline Phases(DAS) & Pan-E & $\begin{array}{r}\mathrm{ET}_{0} \\
\text { (FAO Pan method) }\end{array}$ & $\begin{array}{r}\mathrm{ET}_{0} \\
\text { (PM method) }\end{array}$ & $\begin{array}{r}\text { ETc-wheat } \\
\text { (FAO-Kc method) }\end{array}$ & $\begin{array}{r}\text { AET } \\
\text { (EC method) }\end{array}$ \\
\hline $1-15$ & 51 & 35 & 44 & 31 & $32-38$ \\
$16-40$ & 93 & 61 & 71 & 82 & $42-47$ \\
$41-65$ & 86 & 57 & 69 & 79 & $45-63$ \\
$66-90$ & 119 & 76 & 66 & 99 & $41-59$ \\
$91-105$ & 96 & 61 & 334 & 312 & $28-41$ \\
Seasonal Total & 445 & 290 & 64 & $187-248$ \\
\hline
\end{tabular}

N.B.All units of ET are in mm; ET 0 is reference crop evapo-transpiration; ETc-wheat is reference evapo-transpiration of wheat crop under standard conditions; AET is actual evapo-transpiration of wheat 


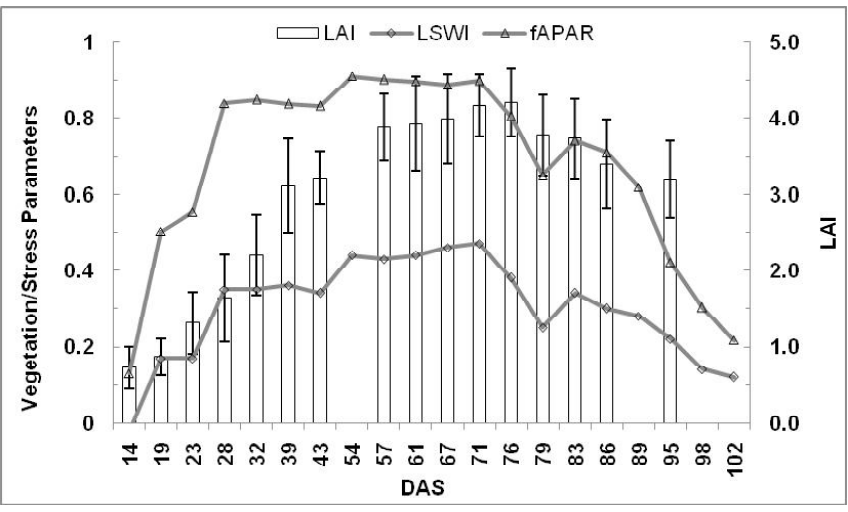

Fig. 2 : Dynamics of leaf area index (LAI) and hyperspectra based vegetation condition or stress parameters (fAPAR, LSWI) during the wheat season (2014-15)

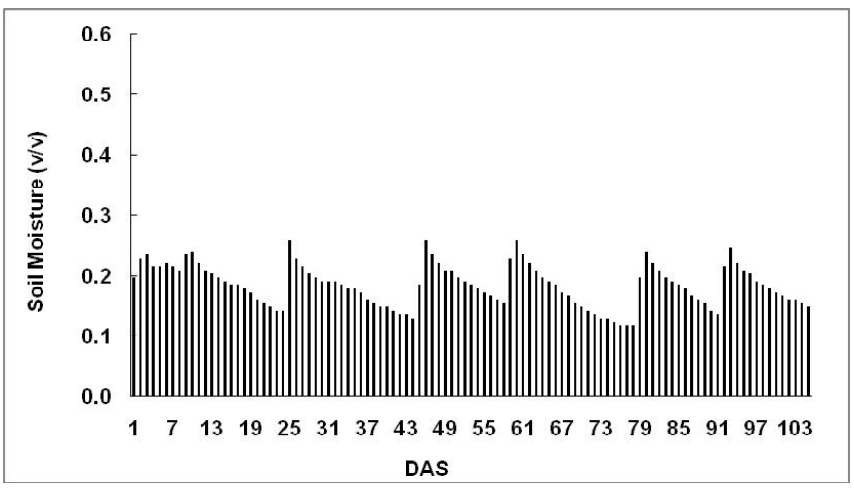

Fig. 3 : Soil moisture cycle during the wheat growing season (2014-15)

\section{Sensible heat flux $(H)$}

Mean rate of $\mathrm{H}$ was found highest $\left(16.2 \mathrm{Wm}^{-2}\right)$ in phase I when the soil was mostly bare whereas the lowest (2.2 $\mathrm{Wm}^{-2}$ ) was observed during phase III when green LAI and canopy vigour were nearing the peaks and two irrigations were applied. Ample water availability at this stage caused much higher proportion of energy to get utilised as latent heat than sensible heat. The effect of crop canopy and irrigation were apparently the cause for low magnitude of $\mathrm{H}$ in phases IV and V despite high level of net radiation intensity. The mean of phase maxima, the mean of phase minima and the overall seasonal mean were found as 103.1 $\mathrm{Wm}^{-2},-31.2 \mathrm{Wm}^{-2}$ and $11.0 \mathrm{Wm}^{-2}$, respectively. As sensible heat flow has direct relevance to air temperature, it may be mentioned here that the averages of daily maxima, daily minima and mean temperatures during the growing period were observed as $29.4{ }^{\circ} \mathrm{C}, 12.8^{\circ} \mathrm{C}$ and $21.1^{\circ} \mathrm{C}$, respectively.

\section{Latent heat flux (LE) and Bowen ratio}

Mean diurnal (day-night) rate of water vapour related energy flux (LE) into the atmosphere was the maximum (56.8
$\mathrm{Wm}^{-2}$ ) during phase I (sowing-CRI) and the minimum (44.2 $\mathrm{Wm}^{-2}$ ) during phase IV (anthesis/flowering-dough) (Table 2). During 15 days long phase I plenty of water was available in the soil due to pre-and post sowing irrigations as well as a total of $44 \mathrm{~mm}$ rainfall spread over four days. Most water loss during phase I was due to bare soil evaporation as the crop cover was minimal (LAI at CRI stage: 0.72 ).In contrast, during phase IV which was of 25 days duration, only one no. of irrigation was provided and limitation of soil moisture for about a week (71-78 DAS) lead to temporary development of canopy water stress. Relatively higher values of mean LE during phase III and phase V compared to phase IV were due to two different reasons. In phase III crop growth was near maximum and two irrigations were provided which facilitated for a high crop evapo-transpiration. In phase $\mathrm{V}$, the crop was at senescence but net radiation was comparatively much higher and irrigation was applied. This might have caused a good amount of water loss through evaporation. LE during phase II was low which could be due to low amount of net radiation and also because only one irrigation was provided in a span of 25 days although the crop was in the active vegetative growth phase.

Irrigations at regular intervals, rainfall events, moderate climatic condition of the study location and good crop cover caused mean LE to be about 3-4 times higher than that of $\mathrm{H}$ through the various phenophases. Except at phase III, when the mean diurnal Bowen ratio $(\mathrm{H} / \mathrm{LE})$ was $<0.1$ i.e. almost the entire energy spent in canopy evapo-transpiration, in other four phenophases it varied within a small range (0.24-0.33) and had a seasonal mean value of 0.23.

\section{Soil heat flux (SH)}

Due to presence of rocks and minerals, which has fairly low specific heat or higher heat transmission rate than the other soil components, within shallow depth $(<50 \mathrm{~cm})$ and application of frequent irrigations, in most part of the diurnal and seasonal cycles heat fluxes were towards the deeper depth i.e. soil acted as a large sink of heat. Maximum rate of heat gain by the soil profile occurred in phase I due to high soil moisture level that increased the specific heat manifold. Similar flux rate was observed in phase III which could again be attributed to high soil moisture. Mean fluxes at phase IV and phase $\mathrm{V}$ of the crop cycle were less negative to slightly positive, respectively. Whereas, in the former, sub optimal moisture condition could be the reason for low heat gain by soil, in the latter case the propensity to loose heat could be driven by high intensity of net radiation. Compared to the total energy spent for $\mathrm{H}$ and LE, energy 

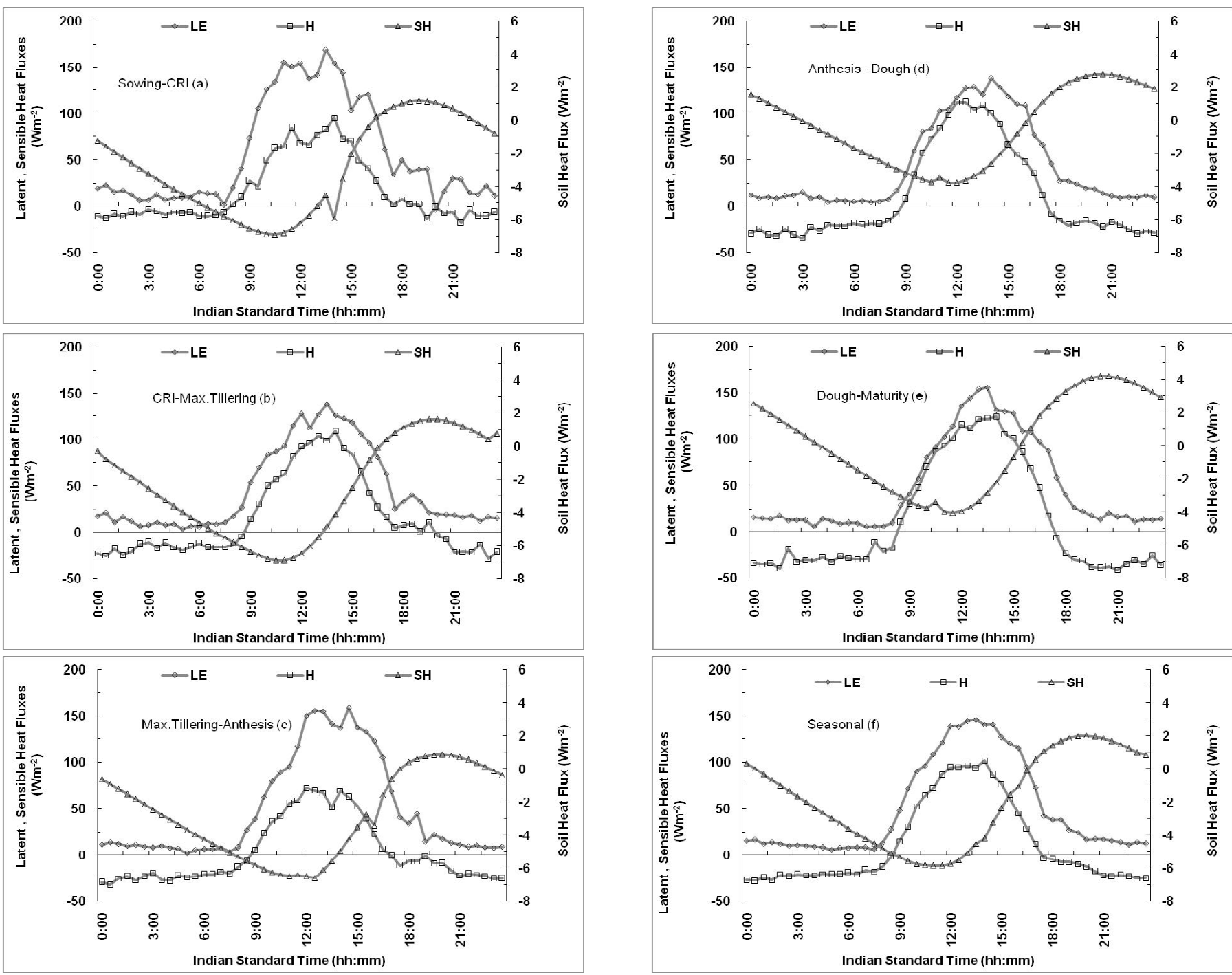

Fig. 4 : Mean diurnal dynamics of heat fluxes (LE- latent heat, H- sensible heat and SH- soil heat) during various phenophases and for the crop season as a whole

consumed as soil heat flux during various phase durations were within $6 \%$ and the seasonal mean was about $3 \%$.

Mean diurnal dynamics (in 24 hours at half-hourly time scale) of the above three energy fluxes i.e. LE, H and SH in various phenophases and for the crop season as a whole is presented in Fig. 4.

\section{Evapo-transpiration, yield and primary productivity}

Estimates of reference crop evapo-transpiration $\left(\mathrm{ET}_{0}\right)$, computed following Allen et al.(1998) and pan coefficient methods using meteorological and some ancillary data as laid down in FAO 56 manual, during the 105 days growing period ranged between $288-334 \mathrm{~mm}$. On the other hand, wheat crop evapo-transpiration under standard conditions (ETc) computed using the aforesaid $\mathrm{ET}_{0}$ and location specific FAO 56 crop coefficient values were in the range of 267-312 $\mathrm{mm}$. Actual evapo-transpiration of the wheat crop, grown under non-standard condition of edaphically stressed environment and estimated using eddy covariance based protocol varied between $187-248 \mathrm{~mm}$ (Table 3 ). The maximum in the AET range was obtained after employing growth phase wise energy balance closure corrections and assuming that the underestimation in turbulent fluxes were due tolatent heat fluxes.

Actual water use of wheat or any crop per se varies depends on many factors. In India, latent heat flux or water use of wheat have been reported under a wide range of growing season lengths (LGPs between 105-150 days), soil type (alluvial, sandy or deep black), timings of sowing (November-December) and harvesting (February-May), atmospheric evaporative demand, wind speed and aerodynamic characteristics of the landscape, irrigation 
frequency and distribution (IW: CPE ranging between 0.61.2), potential yields of varieties $\left(3-6 \mathrm{tha}^{-1}\right)$ and methods of computation (field water balance, lysimetric approach or micrometeorological methods). Some experiments which had been conducted under humid tropical and sub-tropical climates have reported values between 213-290 mm (Bandyopadhyay and Mallick, 2003; Majumdar and Mandal, 1984 and Singh, 1987). In comparison, relatively higher values such as $454 \mathrm{~mm}$ (Prihar et al., 1976) or $337 \mathrm{~mm}$ (Tyagi et al., 2000) and $334 \mathrm{~mm}$ (Singh and Sinha, 1987) were reported from semi arid north India and dry tract of central India. Singandhupe and Sethi (2005) reported extreme high value $(520.7 \mathrm{~mm})$ of actual water use under deep black soil of western Maharashtra. Relatively, lower values of AET in the present study could be attributed mainly to high percolation loss of applied water in the shallow gravelly soil part of the footprint, very low root volume, low evaporative demand of the atmosphere (seasonal pan evaporation rate: $\left.4.2 \mathrm{~mm} \mathrm{~d}^{-1}\right)$ and very short length of the growing period (105 DAS). Dutta and Das (2001) reported similar lower value $(227 \mathrm{~mm}$ ) even under the arid ecological canal command area. Grain harvest at maturity was 3.3 tha $^{-1}$ and the above ground net primary productivity (ANPP) for the 105 days season was $558 \mathrm{~g} \mathrm{C} \mathrm{m}^{-2}$ i.e. $5.3 \mathrm{~g} \mathrm{C} \mathrm{m}^{-2} \mathrm{~d}^{-1}$.Patel et al. (2011) estimated annual cropland gross primary production (GPP) in India through satellite data based production efficiency models. The derived daily GPP rates from their studies varied between 0.5 and $4.1 \mathrm{~g} \mathrm{C} \mathrm{m}^{-2} \mathrm{~d}^{-1}$. Yield based crop NPP during the rabi season of 2008-09 in Punjab districts were reported to vary between 429-618 $\mathrm{g} \mathrm{C} \mathrm{m}^{-2}$ (Saha, 2012).

\section{CONCLUSION}

Evapo-transpiration, actual water use, energy fluxes and canopy stress indicators of wheat was analysed in relation to yield and productivity. Despite the major edaphic constraint of low soil depth and relatively shorter length of the growing period, fairly good net primary productivity and a reasonable grain yield could be achieved through agronomic management. Major proportion of the net radiation energy was spent in latent heat fluxes than the sensible heat due to frequent irrigations and good plant cover. However, the crop was affected by the terminal heat stress and had a low actual water use well below the potential and compared to what it received through rainfall and irrigation. Grain yield and productivity of wheat in the shallow soil of the semi-arid deccan plateau of western Maharashtra can be improved by reducing the evapotranspiration gap through better utilisation of water.
Management practices that encourage better soil development, root volume and ensure higher utilization of applied water by reducing losses such as seepage or deep percolation would be vital for a sustainable wheat production in the region.

\section{REFERENCES}

Allen, R.G., Pereira, L.S., Raes, D., Smith, M. (1998). Crop Evapotranspiration-Guidelines for Computing Crop Water Requirements.Irrigation and Drain, Paper No. 56. FAO, Rome, Italy, p. 300.

Annual Report,DWR(Directorate of Wheat Research, presently Indian Institute of Wheat and Barley Research), Karnal132001, India. (2012-13).pp. 2.

AR5-IPCC (2013). Climate Change 2013: The Physical Science Basis. Working Group I Contribution to the IPCC Fifth Assessment Report.

Baldocchi, D.,Falge, E., Gu, L. etal. (2001). FLUXNET:ANew Tool to Studythe Temporal and Spatial Variabilityof Ecosystem-Scale Carbon Dioxide, Water Vapor, and Energy Flux Densities. Bull.Amer. Meteor. Soc., 82 (11): 2415-2434.

Baldocchi, D.D. (2003). Assessing the eddy covariance technique for evaluating carbon dioxide exchange rates of ecosystem: past, present and future.Glob. Change Biol., 9: 479-492.

Bandyopadhyay, P.K. and Mallick, S. (2003). Actual evapotranspiration and crop coefficients of wheat (Triticum aestivum) under varying moisture levels of humid tropicalcanal command area. Agric. Water Manage., 59: 33-47.

Bhattacharya, P., Neogi, S., Roy, K.S., Dash, P.K., Tripathi, R. and Rao, K.S. (2013).Net ecosystem $\mathrm{CO}_{2}$ exchange and carbon cycling in tropical lowland flooded rice ecosystem.Nutr. Cycl. Agroecosys., 95:133-144.

Burba, G. (2005). "Eddy Covariance Method for Scientific, Industrial, Agricultural, and Regulatory Applications".1stEds. (LI-COR Biosciences, Lincoln, Nebraska).ISBN 978-0-615-76827-4.p. 345.

Dutta, D., Das, D.K.(2001). Water requirement of some crops grown under shallow perched water table at I.G. canal command, western Rajasthan. J. Indian Soc. Soil Sci., 49: $1-6$.

Majumdar, D.K., Mandal, M.(1984). Effect of irrigation based 
on pan evaporation and nitrogen levels on theyield and water use in wheat. Indian J. Agric. Sci., 54: 613-614.

Prihar, S.S., Cheri, K.L., Sandhu, K.S., Sandhu, B.S.(1976). Comparison of irrigation schedules based on panevaporation and growth stages of winter wheat. Agron.J., 60: 650-653.

Saha, S. (2012). Estimation of solar radiation from satellite data for regional primary productivity assessment. Indian Agricultural Research Institute. PhD Thesis. p. 83.

Saha, S., Minhas, P.S., Bal, S.K. and Singh, Y. (2015). Trends in Climatic Features and Greenhouse Exchange of Crops in ScarcityZone (Baramati) of Western Maharashtra. ICARNational Institute of Abiotic Stress Management, Malegaon, Baramati-413115, Pune, Maharashtra, India. Tech. Bull., 6. p. 42.

Sims, D. A., et al. (2006). On the use of MODIS EVI to assess gross primary productivity of North American ecosystems. J. Geophys.Res., 111: G04015. doi:10.1029/ 2006JG000162.

Singandhupe, R. B. \& Sethi, R. R.(2005). Estimation of reference evapo-transpiration and crop coefficient in wheat under semi-arid environment in India. Archives of Agronomy and Soil Science. 51(6): 619-631. doi: 10.1080/ 03650340500273831.

Singh, B.N. (1987). Yield and water use efficiency of bread- wheat under varying levels of irrigation and nitrogen in humid subtropical hills of Meghalaya. Indian J. Agric. Sci., 57:245-250.

Singh, J., Chawla, V., Garg, P. and Gupta, M.(2015). Study of genetic diversity in wheat genotypes using microsatelite markers. Indian Res. J. Genet.\& Biotech., 7(1): 87-92.

Singh, R.D., Sinha, H.N. (1987). Water management practices for wheat. Indian J. Soil Conserv., 15: 101-106.

Singh, R.P.; Rovshan, S.; Goroshi, S.K.; Panigrahy, S.; Parihar, J.S. (2011). Spatial and temporalvariability of Net Primary Productivity (NPP) over terrestrial biosphere of India usingNOAA-AVHRR based GloPEMmodel. J. Ind. Soc. Remote Sens., 39: 345-353.

Tyagi, N., Sharma, D., andLuthra, S. (2000). "Evapotranspiration and Crop Coefficients of Wheat and Sorghum. J. Irrig. Drain Eng., 126(4):215-222.

Webb, E.K., Pearman, G.I., Leuning, R., 1980. Correction of fluxmeasurements for density effects due to heat and watervapour transfer.Quart. J. Roy. Meteor. Soc., 106: 85-100.

Xiao, X., Boles, S., Frolking, S., Li, C., Babu, J.Y., Salas, W. and Moore, B.(2006). Mapping paddy rice agriculture in South and Southeast Asia using multi-temporal MODIS images.Remote Sens. Environ., 100: 95-113. 